Proceedings

\title{
Sage Essential Oil Composition from Kabylia (Algeria) and Its Biological Effects Against Cowpea Weevil (Callosobruchus maculatus) (Coleoptera: Bruchidae) ${ }^{\dagger}$
}

\author{
Karima Taleb-Toudert * and Abdellah Kellouche
}

Citation: Taleb-Toudert, K.; Kellouche, A. Sage Essential Oil Composition from Kabylia (Algeria) and Its Biological Effects Against Cowpea Weevil (Callosobruchus maculatus) (Coleoptera: Bruchidae), in Proceedings of the 1st International Electronic Conference on Entomology, 1-15 July 2021, MDPI: Basel, Switzerland, doi:10.3390/IECE10575

\section{Published: 2 July 2021}

Publisher's Note: MDPI stays neutral with regard to jurisdictional claims in published maps and institutional affiliations.

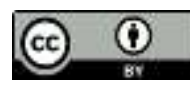

Copyright: (C) 2021 by the authors. Submitted for possible open access publication under the terms and conditions of the Creative Commons Attribution (CC BY) license (http://creativecommons.org/licenses /by/4.0/).

\author{
Sciences Agronomiques, Université Mouloud Mammeri de Tizi-Ouzou, 15000 Tizi-Ouzou, Algeria \\ * Correspondance: ttalebkarima@yahoo.fr \\ † Presented at the 1st International Electronic Conference on Entomology (IECE 2021), 1-15 July 2021; \\ Available online: https://iece.sciforum.net/.
}

\begin{abstract}
The essential oil extracted from sage leaves and stems by steam extraction was analyzed by CGMS. The results obtained indicate high $\alpha$ thuyone $(24.27 \%)$, monoterpenes $(66.66 \%)$, and sesquiterpenes (19.04\%) contents. This essential oil was tested on the eggs of Callosobruchus maculatus (Coleoptera: Bruchidae), a stored foods pest, with different doses: 4, 8, 12 and 16 $\mu \mathrm{l} / \mathrm{L}$ of air.The hatching rate of eggs, the average number of eggs evolved into larvae, and the average number of emergences were estimated by analysis of variance. The study showed that sage essential oil had an impact on the evaluated parameters. Indeed, in the control lots, $97.25 \% \pm 2.5$ of the eggs hatched, while $96.75 \% \pm 1.25$ evolved into larvae. The number of emergence is $96.5 \%$ \pm 1.72 , while the batches treated at the $16 \mu \mathrm{l} / \mathrm{L}$ dose of essential oil air, yielded the following results respectively: $33.5 \pm 4.123 ; 24 \pm 2,38$ and 19,5 $\pm 3,109$. These results are promising for the development of a bioinsecticide based on sage essential oil.
\end{abstract}

Keywords: Callosobruchus maculatus; essential oil; Salvia officinalis; fumigation; bioinsecticide

\section{Introduction}

Algeria is a country characterized by its considerable climate diversification, and for this reason, it abounds in aromatic and medicinal plants.

Among plants with a high added value, a telling example would be legumes. They are rich in carbohydrates, fats and proteins, in proportions 2 to 3 times higher than that of cereals, which makes them compounds of choice in the diet. They are an adequate substitute for animal proteins.

Cowpea seeds, and more specifically the species Vigna unguiculata (L) (walp), is a great example. It is indeed an important source of nutrients in most emerging or developing countries, especially those of Africa and Asia, because of the high protein (23-25\%), starch (50-67\%) and vitamins mature seeds contain [1]. Unfortunately, during storage, cowpea seeds are attacked by rodents, fungi, and insects, especially Callosobruchus maculatus, and losses are very often considerable [2]. For the control of stored food pests, synthetic insecticides or smoke are the most effective methods to keep these pests under control. But the presence of insecticidal residues in stored products, including their accumulation in human tissues, has multiple consequences that can be dramatic. Additionally, the emergence of resistant insect strains resistant is becoming increasingly worrying; nearly 2,000 cases of resistance have been recorded in 504 species; [3].

To cope with the presence of toxic substances, insects have adapted and developed enzymatic systems that allow them to detoxify the harmful compounds to which they are subjected. These enzymatic systems of biotransformation involve oxidation, reduction, and hydrolysis performed by cytochrome P-450 mono-oxygenase and esterase. These 
reactions deactivate or convert the exogenous molecule into a more polar one, which can then be stored or removed from the body [4]. It is therefore important to look for alternative control methods.

Indeed, the use of natural products derived from the secondary metabolism of plants such as essential oils remains an alternative that opens up new prospects to preserve the health of the consumer and the environment. Numerous works have been carried out around the world for the isolation and characterization of the allelochimic compounds used as a defense mecanism by plants with toxic potentialities (alkaloids, terpenes) [5], repellent or anti-feedant compounds in the image of allomones (glucosinolates), [6] or repellents (isothiocyanates) [7] to stored food pests.

It is in this context that our study, which consists in testing under laboratory conditions

the bioinsecticidal effect of sage essential oil (Salvia officinalis) from Kabylie, in Algeria, by fumigation on Callosobruchus maculatus F. (Coleoptera: Bruchidae), is carried out.

\section{Materials and methods}

\subsection{Extraction and chemical analysis of sage essential oil}

Sage leaves and stems $(20 \mathrm{Kg})$ were collected in April 2018 in a village in Kabylie at an altitude of $600 \mathrm{~m}$. The leaves and stems were dried at room temperature for one week ( 7 days). The essential oil was extracted by the water vapour drive technique by a pilot extractor for 3 hours with a $0.2 \%$ yield. It appears to be a colourless liquid with a camphor-like odour and a pungent flavour.

For the identification of the volatile compounds of the extracted oils, we used the gas chromatography technique coupled with mass spectrometry at INRAP (Institut national de Recherche et d'Analyses physicochimiques, Technopole Sidi Thabet, in Tunisia).

The GC/MS device is an agilent one and the injection system is the split splitless. The length of the column is $30 \mathrm{~m}$, its diameter is $0.25 \mathrm{~mm}$ and the column is $0.25 \mu \mathrm{m}$ thick.

The initial temperature of $40^{\circ} \mathrm{C}$ is maintained for one minute. The temperature increases by $2^{\circ} \mathrm{C} / \mathrm{min}$ to $240^{\circ} \mathrm{C}$. The temperature is maintained for 20 minutes. The temperature in the injector and interface is $250^{\circ} \mathrm{C}$, the source temperature is $230^{\circ} \mathrm{C}$.

The total ion chromatogram is recorded using an electronic impact source and the kinetic energy of the ions is $70 \mathrm{eV}$. The standards were identified by the spectral masses for the US National Standards Institute.

The results of the analyses of essential oils are presented in the form of a chromatogram and a report by Database/ Nist (National Institute of Standard and Technology).

The chromatogram shows several peaks. Each peak is represented by a retention time that represents the nature of the essential oil compound and a percentage of the peak area that constitutes the percentage of the oil compound relative to the other compounds.

As for Database NIST reports, this is a table that groups the characteristics of each chromatogram peak (essential oil), according to the $\mathrm{C} / \mathrm{msd}$ chem/1Method/HP16 HE method. SAM-0.1M.

After identifying the different constituents of the essential oil, terpenic compounds were classified according to the number of $\mathrm{C}_{10}$ units they contain, relative to the total number of compounds of each essential oil (monoterpenes: $\mathrm{C}_{10} \mathrm{H}_{16}$; sesquiterpenes: $\mathrm{C}_{15} \mathrm{H}_{24}$ and diterpenes: $\mathrm{C}_{20} \mathrm{H}_{32}$ [ 8].

\subsection{Insects}

Mass breeding of Callosobruchus maculatus for bioassays was carried out in the entomology laboratory of Mouloud Mammeri University (UMMTO), in the oven at a temperature of $30 \pm 1^{\circ} \mathrm{C}$ and a relative humidity of $70 \pm 5 \%$. 


\subsection{Cowpea seeds}

The healthy seeds of Vigna unguiculata used for mass breeding and bioassays come from an organic farm located in the region of Tirmitine in Kabylie in the wilaya of Tizi- Ouzou (Algeria).

2. 1- Evaluation of the toxicity of Sage EO by fumigation on the biology of C. maculatus

The effect of different doses of sage EO applied by fumigation on the development of eggs under $24 \mathrm{~h}$ and the monitoring of the different life stages of the individuals that emerged was carried out.

\subsubsection{Treatment by fumigation}

This test consists of studying the evolution of 100 eggs less than $24 \mathrm{~h}$ subjected to the action of the different doses of essential oil of S. officinalis $(4 \mu \mathrm{l}, 8 \mu \mathrm{l}, 12 \mu \mathrm{l}$, and 16 $\mu \mathrm{l})$, by fumigation for 45 days.

1 liter volume glass jars were used. Pieces of $4 \mathrm{~cm}$ diameter filter paper $\mathrm{n}^{\circ} 1$ were attached by a wire to the centre of the covers, while the oil doses were injected on the filter paper. A control was conducted in parallel to this trial. 100 eggs were laid on the seeds in less than $24 \mathrm{~h}$. They were quickly put in the jars described above, then sealed hermetically with adhesive tape.

After 24 hours, the seeds are removed and placed in glass Petri dishes of $15 \mathrm{~cm}$ diameter and $2 \mathrm{~cm}$ height. They are heated to a temperature of $30 \pm 1^{\circ} \mathrm{C}$ and a relative humidity of $70 \pm 5 \%$. 04 replicates were performed for each EO doses. six.

Hatched eggs were counted using a binocular magnifying glass from day one to day

\subsubsection{Studied parameters}

- Hatching of the eggs

The hatched eggs and non-hatched ones laid on the seeds are counted starting day 15 from the start of the test, under a binocular magnifying glass $(G \times 40) .100$ eggs were used in each test. So the hatching rate is calculated by the following formula :

Egg hatching rate $=($ Number of eggs hatched $/ 100) \times 100$

The determination of the lethal doses that cause 50\% eggs mortality (LD50) was carried out by graphing the regression line $y=a x+b$ by transforming the corrected egg hatching rates into probits and the dose values into decimal log.

Fiducial limits (95\%) for $\mathrm{LD}_{50}$ was calculated in order to situate the lethal dose which achieve $50 \%$ C.maculatus hatching eggs.

- Number of larvae

The regular counting of the larvae, starts from the 15th day until the 25th day.

- Emergence

The first-generation offsprings were counted from the 25th to the 45th day of the start of treatment.

The viability rate is calculated by the following formula:

Egg viability rate $=($ Number of adults emerged $/$ Number of eggs hatched $) \times 100$.

\subsubsection{Statistical analysis}

The results were subjected to the ANOVA test according to a single classification criterion. When the effect of the treatments is significant, the analysis is completed by the test of Newman and Keuls at $5 \%$ (Logiciel Stat box ; [9]).

\section{Results}

3.1. Extraction and chemical analysis of sage essential oil 
Sage essential oil is a colourless liquid with a camphor-like odour and a pungent flavor with a $0.2 \%$ yield.

The biochemical analysis of the essential oil reveals the predominance of three compounds namely $\alpha$ tuyone $(\mathbf{2 4 . 2 7 \% )}$, camphor $(\mathbf{1 8 . 1 0} \%)$ and $1-8$ cineol $(\mathbf{1 4 . 3 8} \%)$, but there are also other compounds with medium or low proportions such as $\beta$ thuyone (7.38\%) camphene $(4.14 \%)$ caryophyllene oxide ( $4.96 \%)$, Limonene (3.25\%).

The analysis of variance shows that the oil doses used affect C.maculatus eggs in a very highly significant way $(\mathrm{P}=0.0000, \mathrm{~F}=266.115)$. Thus, the average hatching rate in the control lots is estimated at $97.25 \%$. This rate decreases with injected sage EO doses to reach an average rate of $33.50 \pm 4.12$ at the highest dose of $16 \mu 1 / 1$ air.

The Newman and Keuls test that completed this analyses produced the histograms in figures

5,7 , and 8 which show a decrease on $C$. maculatus hatching eggs, their evolution to larvae and in the adult emergence as the EO dose increase.

The $\mathrm{LD}_{50}$ deduced from the regression line is $6.38 \mu \mathrm{l} / 1$ air.

The fiducial limits calculated are $4.42 \mu \mathrm{l} / 1$ air and $8.34 \mu \mathrm{l} / 1$ a

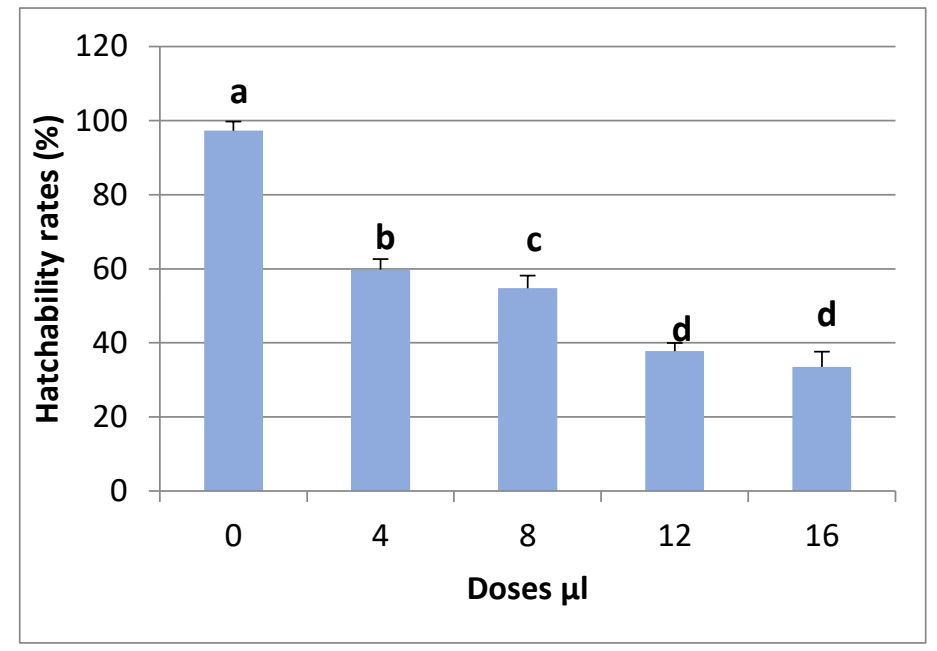

Figure 5. Rates of egg hatchability values ( \pm standard deviation) observed in C. maculatus after. treatment with $S$. officinalis EO by fumigation as a function of dose ( $\mu \mathrm{l} / \mathrm{l}$ air) (The averages followed by different letter are very significantly different, according to the Newman and Keuls test, at the $\mathrm{P}=5 \%$ level)

- Action on the evolution of eggs into larvae

The evolution of the eggs of the control batches into larvae is estimated at $96.75 \%$, this rate decreases while doses increases.

The analysis of the variance shows that the oil doses used affect in a very significant way $(\mathrm{P}=0.0000 ; \mathrm{F}=405.358)$. This rate shows a clear decrease with the sage EO treatment. Indeed, the average rates fall as the dose of EO increases to reach $24.50 \% \pm 2.58$. Fig.6. 


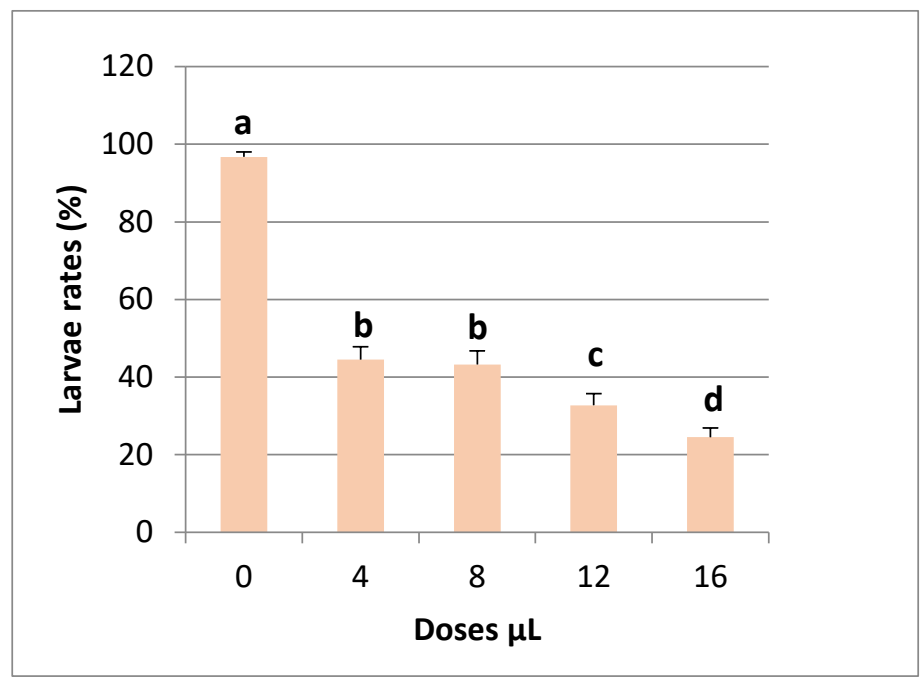

Figure 6. Rates values ( \pm standard deviation) of $C$. maculatus larva observed after treatment with $S$. officinalis EO by fumigation as a function of dose ( $\mu \mathrm{l} / 1$ air) (The averages followed by different letter are very significantly different, according to the Newman and Keuls test, at the $\mathrm{P}=$ $5 \%$ level).

- $\quad$ Action on the emergence

Statistical analysis of the obtained results shows that the emergence rate depends on the dose of oil used. In the control

batches, the average rate of emerged adults is $96.5 \% \pm 1.73$. This rate decreases in the case of eggs subjected to the inhalation action of sage oil with decreasing emergence rates to reach $19.5 \% \pm 3.10$ at $16 \mu \mathrm{l} / \mathrm{l}$ air dose.

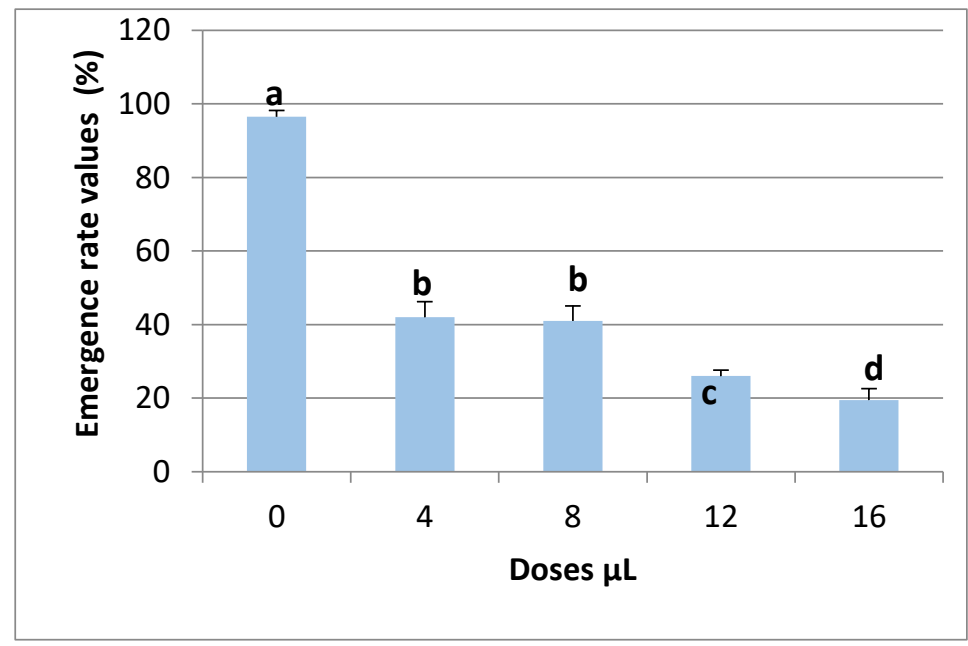

Figure 7. Rate values ( \pm standard deviation) of $C$. maculatus emergence observed after treatment with $S$. officinalis EO by fumigation as a function of dose ( $\mu \mathrm{l} / 1$ air) (The averages followed by different letter are very significantly different, according to the Newman and Keuls test, at the P= $5 \%$ level).

\section{Discussion}

The main components of S.officinalis are $\alpha$-thuyone with a $24.27 \%$ rate, camphor with $18.10 \%$ rate, eucalyptol $(14.53 \%)$ and $\beta$-thujone $(7.38 \%)$. At the same time, other sesquiterpene compounds exist, such as limonene $(3.25 \%)$, camphene $(4.14 \%)$, caryophyllene $(4.96 \%)$ or humulene $(2.83 \%)$. 
The richness of the extracted EO in $\alpha$ thujone (24.27\%), eucalyptol $(14.53 \%)$ and camphor $(18.10 \%$ ) would pose it as an $\alpha$ thujone / camphor /eucalyptol chemotype. The latter was not cited by [10] in defining the five chemotypes of S.officinalis.

All the chemical compounds of sage HE revealed by CG:MS have often been characterized by their biocidal and repellent activity against many insects pests of the stored food [11], [12]. [13]showed the richness of S.officinalis in $\beta$ thuyone with $28 \%$, Linalyl acetate $21.4 \%, \beta$ caryophyllene and $\alpha$ humulene 5\%. Many authors argue that there is a correlation between the chemical composition of essential oils and variation in biotic and environmental factors. Thus the geographical origin, the phenological stage of the plant; the method of extraction, the nature of the soil... etc would strongly impact the chemical composition of essential oils.

[14] showed a variation in the chemical composition of Diphasia klaineana Pierre (Rutaceae) essential oil in relation to flowering. Thus, the essential oil extracted from the leaves before flowering is richer in monoterpene hydrocarbon compounds with $45.88 \%$, while that extracted after flowering contains $34.61 \%$, but was found to be richer in oxygenated sesquiterpenes $(56.95 \%)$ compared to the oil extracted before flowering $(38.36 \%)$. This variation is the result of many metabolic and physiological mechanisms : biosynthesis, degradation, transport, accumulation and bioconversion capacity Thus, the hatching rates recorded in the batches subjected to the vapours of sage essential oil are $33.5 \%, 37.75 \%, 54.75 \%$, and $59.75 \%$ for the respective doses of EO Sage $(4,8,12$ and $16 \mu \mathrm{l} / \mathrm{l}$ air), compared to the control at $97,25 \%$. This could be due to the presence of two compounds at high concentrations : Thuyone and eucalyptol. Thuyone is a volatile monoterpenic ketone produced by many plant species. [15] reported that the most known neurotoxic effects are related to the GABA-dependent chloride channel. The neurotoxicity mechanism of thuyones has been extensively studied in animals, cultured neuronal cells and expressed receptors. The results of our study show that the hatching parameter of eggs is greatly affected as the dose of essential oil increases. Our results are consistent with those of other authors, as [16] showed biocidal activity of S. officinalis after 24 hours of exposure to C. maculatus at a concentration of $15 \mu \mathrm{L} / 1$ air. [17] reported that a study related to the determination of the insecticidal potential essential oils from Sri Lanka against the cowpea weevil $C$. maculatus raised on the seeds of Vigna radiata has revealed the essential oil from black pepper seeds ( P. nigrum ) $0.8 \%$ caused total oviposition inhibition and $0.2 \%$ caused high adult mortality of $C$. maculatus. The rate of evolution of eggs into larvae is very highly affected (24.5\%) at the highest dose of $16 \mu \mathrm{l} / \mathrm{l}$ air, this would be only the consequence of the reduction of the number of eggs hatched to $33.5 \%$ and probably the intervention of thuyone and eucalyptol. Similarly, [18] reported that 1-8 cineole is neurotoxic, which has a negative impact on development by inhibiting the development of S. zeamaïs and S.granarius eggs, larvae and nymphs on wheat.

\section{Conclusion}

The sage essential oil from Kabylie is an extracted chemotype $\alpha$ thujone / camphor / Eucalyptol. This oil demonstrated a very significant impact on the different biological parameters of the $C$. maculatus life cycle by fumigation.

However, as with all other insecticidal molecules, precautions must be taken by users and toxicological studies are required.

\section{References}

1. Chaux, C. ; Foury, C. Les productions légumières.Tome 1. Ed. Lavoisier / Tec et Doc, Collection Agriculture d'aujourd'hui, France, 1994 ; pp. 548.

2. Tapondjou, L.Z. ; Adler, C.; Bouda, H. ; Fontem, D.A. Bioefficacy of powders and essential oils from leaves of Chenopodium ambrosioides and Eucalyptus saligna to the cowpea bruchid, Callosobruchus maculatus Fab.(Coleoptera: Bruchidae) Cahiers d'études et de recherche francophones /Agricultures $2003,12(6), 401-407$. 
3. Georghiou, G.P. ; Lagunes Tegeda, A., The occurrence of resistance to pesticides in arthropods. Food Agriculture org.Union Nations Rome, 1991; AGPP :MISC /91pp.1-318.

4. Vos, R.M. ;Van Bladeren, P.J. Glutathion Stransferases in relation to their role in the biotransformation of xenobiotics. Chem. Biol. Interact 1990, 75(3), 241-265.

5. Harborne, J.B. Introduction to Ecological Biochemistry.4th ed.; Academic Press1993; pp.318.

6. Schoonhoven, L.M. ; Derksen-Koppers, I. Effects of some allelochemics on food uptake and survival of a polyphagous aphid, myzus persicae. Entomol. Exp. Appl. 1976, 19 (1), 52-56

7. Blau, P.A.; Feeny, P. ; Contardo, L. ; Robson D.S. Allylglucosinolate and Herbivorus caterpillars: A contrast in toxicity and tolerance. Science. New series, 1978; 200 (4347) ),pp. 1296-1298

8. Guignard, J.L. ( 2004 ) Biochimie végétale, deuxième édition Dunod Paris. pp : 162- 194.

9. Dagnelie, P. Théories et méthodes statistiques. Vol. 2. Les presses agronomiques de Gembloux, Belgique, 1975, pp. 245-249.

10. Craft, J.D., Saryal, P. ; Seltzer W.N. The chemotaxonomy of common sage (Salvia officinalis ) based on the volatile constituents Medecines(Bases), 2017, pp. $4-47$.

11. Kéîta, S.M.; Vincent, C.; Schmit, J.P; Ramasway, S.; Belanger, A. Effect of

12. various essentials oils on Callosobruchus maculatus (F.) (Coleoptera : Bruchidae). J.Stored Prod. Res. 2000, 36, 335-364.

13. Kellouche, A.; Soltani, N.; Kreiter, S.; Auger, J.; Arnold, I.; Kreiter, P. Biological

14. activity of four vegetable oils on Callosobruchus maculatus (Fabricius) (Coleoptera: Bruchidae). Redia 2004, LXXXVII, 39 - 47.

15. Regnault-Roger, C.; Hamraoui, A.; Holeman, M.; Theron, E. ; Pinel, R.

16. Insecticidal effect of essential oils from Mediterranean plants upon Acanthocelides obtectus. J. Chem. Ecol. 1993, $19,1233-1244$.

17. Kone, y.; Boua Boua, B.; Ouattara, Z.; Mamyrbekova-Bekro, J.A ; Bekro, Y.A.

18. Influence de la floraison sur la composition chimique et l'activité anti sinusite de l'huile essentielle des feuilles de Diphasia Klaineana Pierre ( Rutaceae) de Côte d'Ivoire . J. Appli. Biosc. 2019, 135, 13742-13749

19. Zamboriné- Németh, E.; Thi Nguyen, H. Thujone, a widely debated volatile

20. compound: What do we know about it. Phytochem. Rev. 2020, 19, 405-423.

21. Kellouche, A.; Ait aider, F. ; Labdaoui, K. ; Moula, D. ; Ouendi, K. ; Hamadi, N. ; Ouramdane, A. ; Frerot B. ; Mellouk M. Biological activity of ten essential oils against cowpea beetle Callosobruchus maculatus Fabricius (Coleoptera : Bruchidae). Int. J. Integr. Biol. 2010, 1, $86-89$.

22. Rajapakse, R.h.S. the effect of four botanicals on the oviposition and adult emergence of Callosobruchus maculatus F. (Coleoptera: Bruchidae). Entomon 1996, 21, 211-215.

23. Obeng-Ofori, D.; Reichmuth, C.H.; Bekele, J. ; Hassanali, A. Biological activity of

24. 1.8 cineol, a major component of essential oil of Ocimum kenyense against stored product beetles. J. .Appl. Entomol. 1997, 121, 237- 243. 